\title{
Promoting diversity in Creative Art Education: The Case of Fine Art at Goldsmiths, University of London
}

\begin{abstract}
Students studying Art at university in the UK tend to be female, from higher social classes and from majority ethnic groups. This paper considers some of the complex and deeply-rooted social and economic factors that militate against wider participation in the arts and describes how we started to tackle under-representation at Goldsmiths using a participatory action research approach. Working in partnership with local colleges, the project aimed to increase student diversity and widen participation to the Goldsmiths BA Fine Art Degree. The need for university applicants to have the 'right sort' of cultural capital is particularly marked in Fine Art, indicating that standard widening participation aspiration-raising activities would not solve the problem. A range of interventions were developed to support potential applicants, underpinned by participatory action research. The flexibility and responsiveness of the research model allowed us to reflect on and respond to issues as they arose and achieve immediate positive impact.
\end{abstract}

Key words: higher education, art education, widening participation, cultural capital, diversity, participatory action research.

Words 7999

\section{Introduction}

Although Goldsmiths has a strong tradition of widening participation (WP) there is considerable variation across departments in terms of ethnicity, gender and social class, strongly related to the selectivity of the degree and the symbolic value of the subject. First, many potential applicants from groups currently under-represented in UK higher education (HE) who have the potential to succeed, do not meet the entry requirements. (Sutton Trust 2011). In addition, as Boliver (2011) found, the culture and practices of selective universities exclude students from lower social classes. Also, as Bourdieu (1993) recognised, the world of Fine Art is particularly exclusive, marked by the cultural privilege associated with 
understanding and deciphering socially-constructed meanings and codes. Recognising that these factors have a direct impact on student diversity on the BA Fine Art at Goldsmiths, we developed a new approach to widening access. Through a participatory action research project Diversity in Creative Arts (DCA) focussing on one institution, we explored both the wider context and the very specific institutional cultural practices and processes that lead to the exclusion of certain groups. This article describes the intiative and the subsequent changes to outreach activities and admissions practices that were introduced as a result.

\section{Selection and Participation}

The Fine Art BA at Goldsmiths is a highly selective course; in 2010/11 there were 70 places for approximately 1,400 applicants. As with similar courses nationally and other London-based ${ }^{1}$ courses, the majority of Goldsmiths Fine Art students are female, white and middle-class. HEIDI (Higher Education Information Database for Institutions) data for 2008/9 reveal stark disparities in terms of gender, class and ethnicity. Nationally, $72 \%$ of undergraduates taking Fine Art are female and 28\% male with Goldsmiths students comprising $65 \%$ female and 35\% male. Nationally, $63.7 \%$ of Fine Art students were in SocioEconomic Groups (SEGs) 1-3 and 36.3\% in SEGs 4-7 compared to 72.7\% and 27.3\% respectively at Goldsmiths. The national data on ethnicity show that $91.6 \%$ of students taking Fine Art are 'white' whilst this figure is $92.3 \%$ at Goldsmiths.

Despite a range of reforms introduced over the last 50 years by UK governments to encourage wider participation in higher education, social division remains an entrenched feature of the system, particularly in selective universities (Harris 2010; Archer, Hutchings

\footnotetext{
${ }^{1}$ UCL SLADE School of Art: University of the Arts London Fine Art Colleges: Camberwell College of Arts, Central St Martin's College of Arts and Design, Chelsea College of Art and Design, Wimbledon College of Art.
} 
and Ross 2003; Vignoles and Crawford 2010). Even the full maintenance grant, introduced following the Robbins report in 1964, had limited impact on the low proportion of working class students undertaking university study.

In recent years there has been greater recognition by UK governments of the impact that cultural and social factors have on HE participation in the UK. The New Labour government of $1997-2010$ drew on the work of social capital theorists such as Coleman (1988) and Putnam (1995) to underpin its social policy resulting in a number of initiatives including Aimhigher, which had the specific aim of addressing social inequalities in HE. These policies have been criticised for being based on 'deficit' models, where white, middleclass values typify the 'right sort' of social capital (Burke 2012; Gewirtz 2001; Ecclestone and Field 2003; Leathwood and Hayton 2002; Gamarnikow and Green 1999).

In contrast to these rather static 'deficit' formulations of social capital, a Bourdieurian framework recognises that while all individuals possess social and cultural capitals they do not have the same symbolic value, significantly impacting on an individual's position within society. Bourdieu uses the concepts of habitus and field to explore how individuals' backgrounds and experiences shape their choices and life chances. Habitus can be described as:

'the way society becomes deposited in persons in the form of lasting dispositions, or trained capacities and structured propensities to think, feel and act in determinant ways, which then guide them' Wacquant (as quoted in Navarro 2006, 16).

Where habitus and field are closely related, an individual feels confident and comfortable - like 'a fish in water' (Bourdieu and Wacquant 1992). Field can be defined as the social setting in which activities take place. When a habitus encounters an unfamiliar field, individuals feel uncomfortable and uncertain. However, as Robbins (2000) points out: 
'... the habitus embodies the attitudes which we inherit, but it does not constitute a stimulus which conditions how we behave.' (Robbins 2000, 29). Reay, David and Ball (2005), recognising that active choice is at the heart of habitus, apply the concept to higher education choice, identifying two 'ideal- types' of HE applicants: 'embedded' choosers who possess the economic, social and cultural capital to support progression to university and 'contingent' choosers who do not have these advantages.

Field has also been important in understanding students' choices about university environments, explaining why 'fitting in' is so critical in their higher education decisionmaking process (Reay, Crozier and Clayton 2009). Informed by the work of Bourdieu, DCA explicitly rejected a 'deficit' approach, recognising that personal and societal change can only take place when individuals move into new situations or fields, requiring them to actively engage, question and reinterpret. A fundamental principle of DCA was the need for Goldsmiths staff and processes to change in order to address the challenge of increasing diversity on the Fine Art BA.

The class-based acquisition of 'high' art culture and discourse, combined with the precarity of earning a living in a volatile art market make Fine Art one of the most socially exclusive subjects. Paradoxically, because of its valorisation of originality, the benefits of a privileged - but standard - middle class education are very mixed. Many of the artists producing the most dynamic radical art are working class, notably Damien Hirst, Sarah Lucas and Tracey Emin, and from under-represented cultural groups, for example Mona Hatoum (Palestinian) and Yinka Shonibare (Nigerian/ UK). All have contributed their own specific cultural capitals which have transformed and acted on the field itself and radically expanded the discourses, practices and paradigms of contemporary art. If the particular social and cultural capital of outsiders is recognised and nurtured then their 'discomfort' in an unfamiliar field can be transformed into active engagement, questioning and reinterpreting the values 
inherent in existing practices and discourses and enabling them to develop further in their own practice.

Goldsmiths BA Fine Art admissions criteria are not based on A-Level scores but on a portfolio of independent artwork and an interview. Applicants must demonstrate commitment to art and development of their practice, ambition, self- motivation and also value discussion of their work. Whilst disregard for academic qualifications appears to offer a level playing field to applicants, the capacity to demonstrate embedded knowledge and understanding of a high cultural field are qualities which Bourdieu identified as the preserve of the privileged classes.

'Owing to the particular status of the work of art ....individuals are endowed with a previously acquired competence and with a whole capital of experience unequally distributed among the various social classes (visits to museums or monuments, attending concerts, lectures, etc.) (Bourdieu, 1993. 231).

An applicant's ability to question the status quo of the field is one of the 'unspoken' criterion for acceptance on the Goldsmiths BA in Fine Art. Bourdieu highlights the exclusivity of this ability:

'The contrast between accepted, stereotyped and 'routinized' culture, and genuine culture freed from school discourse, has meaning only for an infinitely small minority of educated people for whom culture is second nature...' (ibid. 231).

Bourdieu describes the field of cultural production as a site of struggle where the power to impose the dominant definition of the artist is at stake. As with admissions requirements, the characteristics of the boundary of the field are institutionalised; protected by conditions of entry that are tacitly and practically required, or explicitly codified and legally guaranteed. For 'contingent' choosers, the emphasis on specific cultural capital discriminates at an 
unspoken level as the actual condition of entry is a highly developed mastery of the field in practical and theoretical terms.

\section{Methodology}

The DCA initiative was designed to create a reflexive and transformative space to explore factors affecting prospective students' prior artistic development and decision-making processes alongside the impact of outreach strategies and admissions practices. While the focus on one university has obvious limitations, we were able to explore processes in depth and illustrate the complexity of institutional change in a very specific policy context. We adopted a participatory action research model as it most closely reflected our desire to interrogate and challenge existing practices. As Reason and Bradbury (2008) explain: 'Action Research does not start from a desire of changing others 'out there' ... rather it starts from an orientation of change with others'(1). Somekh and Zeichner (2009) regard Action Research as a potent methodology for educational reform precisely because its core principle of combining action with research inevitably challenges the routines of the status quo (19). Through constant dialogue between partners we developed a dynamic, iterative model with the capacity for reflexivity and positive action. Somekh and Zeichner (ibid.) describe this process in terms of 'interpenetrating reflexive spirals of action research' (6).

The core DCA team included Goldsmiths staff from Departments of Art, Educational Studies and Widening Participation (WP) and a part-time research assistant. Other key players were students and staff in the FE colleges and Goldsmiths Student Ambassadors. The involvement of current Student Ambassadors in widening participation outreach activities is now standard practice in most universities. Originally deployed to give the occasional talk about 'university life', the role of the Ambassador has developed to include involvement in delivery of complex outreach activities, often in a paid capacity. The DCA team planned a 
programme of interventions, research and points for reflection over a 15 month period (Heisanken 2007, 182).

DCA outreach interventions included planned visits to the university, ambassador-led portfolio workshops, support with university applications, interview practice and a summer school. Dissemination to Goldsmiths and FE staff was built into the project plan to support change in other departments.

The research had three distinct elements:

- 'Illuminate' a small-scale, qualitative SARs (Students as Researchers) project with students at Lewisham College;

- An online survey, combined with interviews and focus groups, with students and staff from four other local FE colleges;

- Spaces for the DCA team to reflect on research and reformulate activities.

'Illuminate' methodology enables exploration of issues and ideas arising from a particular group and was used to good effect with 25 students from the Lewisham College Art Foundation Diploma ${ }^{2}$. participating in DCA outreach interventions It provided qualitative data resulting in changes to the planned outreach interventions and structured the second stage of the research. The process also established a close working relationship with the art lecturers at Lewisham which was critical to the success of the project. The 'Illuminate' report (Carlile 2010) identified five key themes as challenging areas for prospective applicants:

- Developing the skills and confidence to engage in constructive critical analysis;

- Funding higher education studies, value for money and career outcomes;

- Finding the time and resources to develop a good portfolio;

- Having timely and accurate information about courses and application processes;

\footnotetext{
${ }^{2}$ Normally taken after A Levels as a preparation for a degree in art
} 
- Developing skills in oral presentations, writing UCAS statements and interviews.

How we located, understood and acted on these five themes is a good example of the reflexive and transformational process taking place within DCA. Although the points are calls to action, they are also the concrete expressions of students who have actively chosen to take an HE preparation course, placing themselves in a context where their habitus is challenged. Reay, Crozier and Clayton (2009) describe the 'shock of the elite' as students' working class habitus meets the middle class field of the elite university; 'Unlike their middle-class counterparts they are engaged in [conscious] acts of invention, or rather reinvention...' (1110). DCA actively created the space for students to reflect on and recount their perceptions and the five themes emerging provided the basis for the second phase of research. This centred on an online survey conducted at four London FE colleges offering both the Art Foundation Diploma and the BTEC National ${ }^{2}$ Diploma in Art and Design, usually taken as an alternative to A-Levels. Facilitated group discussions were carried out with students and informal discussions were held with course tutors about the application process and their perceptions and knowledge of Goldsmiths. A similar survey was completed by approximately one third of the Goldsmiths undergraduate Fine Art students and a facilitated group discussion was held with Fine Art Student Ambassadors.

The survey was commissioned to challenge the prevailing discourse that admissions processes were 'fair' and purely about individual talent. Sample data gathered from 188 students across three course levels revealed some interesting local issues relating to the interaction between class, gender, ethnicity, educational attainment and qualifications.

In terms of gender, the figures at A-Level, Foundation and university level were broadly reflective of the national picture although the six BTEC classes presented a more balanced picture with 55\% female and 45\% male. BTEC students were four times more likely 
to have a parent who was unemployed than Foundation Year or degree students. Goldsmiths undergraduates were more than twice as likely as those on the BTEC course to have at least one parent who was university educated. The data gave a stark illustration of the differences in the ethnic make-up of student bodies at different levels of study. The most significant differences were found between students taking A-Level and BTEC where 24\% described themselves as white and those on the Foundation Diploma, with 63\% describing themselves as 'white' and Goldsmiths students where $76 \%$ described themselves as 'white'.

Combined with the qualitative data, the survey illustrated the complex and multilayered interaction between personal and structural issues and the effect on choice, decision-making and entry to higher education. The findings are explored in the following section under five main themes: Finance and Employment; Fitting-in; Qualifications and Education; Applying to Goldsmiths; and Creativity and Commitment.

\section{Finance and Employment}

Financial concerns were expressed most commonly in relation to career prospects, the repayment of student loans and the guarantee of future income. Writing in 2004, Archer and Hutchings found that working class students 'constructed university as a 'risky' and 'costly' option' (571). BTEC students in our sample tended to favour courses with a direct career path such as animation or graphic/interior design. Anxiety about perceived lack of job opportunities for Fine Art graduates was a major consideration for them and their parents:

'My mum keeps pushing me to go into graphic design or some kind of art that I can like, sell directly' (BTEC National Diploma student, female)

Our findings corresponded closely with Bourdieu's analysis in 'Habitus and the Possibles' where he wrote: 
'The propensity to move towards economically most risky positions and above all the capacity to persist in them ...depends to a large extent on possession of substantial economic capital (as well as social capital)' (op cit 1993, 67)

Regardless of background, permanent jobs as a fine artist are very limited. As the UK's official graduate careers website (www.prospects.ac.uk) states, 'it takes most fine artists five to ten years to become established and to have a practice that makes a viable living'. The majority of successful artists (in terms of commanding a good salary) are men, with very few women or BME artists achieving similar levels of critical acclaim or associated high earnings, which is paradoxical given the predominance of female students. In the UK, only four out of the twenty-seven Turner Prize winners have been women and only three of the twenty-seven are artists from BME backgrounds.

Despite the success of white male artists, Fine Art is not a path normally open to working class boys of any ethnicity, caught in the double bind of pressure to conform to culturally prescribed notions of masculinity alongside the pressure to choose a 'good' (vocational) course. Art is strongly associated with the feminine (Francis 2000) and ambivalence about studying appropriate subjects to maintain certain masculine identities is an important element in subject choice. Archer and Leathwood (2003) found that for many (white) working class men 'positive' manual work identities were directly contrasted with 'brain' (academic) work, which was derided (181). In the case of art, the class divisions between 'mental' and 'manual' labour are manifested through the distinctions between 'fine art' and 'craft', actively constructed over centuries to reinforce and uphold social and economic divisions.(Sennett 2009, 65). As Bourdieu explains:

... the elaboration of pure forms [of art], generally considered the most noble, presupposes the disappearance of all functional characteristics and all reference to 
practical or ethical goals' (as quoted in Robbins 2000, 12)

These issues often have even greater impact on the identities and choices of minority ethnic groups (Shiner and Modood 2002). The perceived value of education within different cultures varies according to religion, 'race', social class, income and gender. As Burke (2006, 731) concludes from her research on men accessing education; '.....aspirations are not constructed on an individual level but are tied-in with complex structural, cultural and discursive relations and practices'.

The students' lack of accurate knowledge about careers in the arts was a strong theme throughout, relating both to careers advice and the marketing of Fine Art courses. DCA illustrated at a very basic level students' need for more information about the differences between University Fine Art courses and what might be right for them. In 'Art for a Few' (2009), Burke and McManus contrast the information that students from different backgrounds are able to access. Whilst 'contingent' choosers are generally restricted to hard information (prospectus/website), it was recognised that reliable 'soft' information available to 'embedded' choosers (e.g. family and school connections to alumni and practising artists), is much more helpful. Similarly, our research indicated that limited access to reliable 'soft' information put local students at a severe disadvantage in the application process. This was an important learning point for the Art Department prompting a discussion about what constitutes 'fair' access and how to tackle the poor knowledge base of local students about the available opportunities.

\section{Fitting in}

Our exploration of 'fitting-in' brought habitus as a theoretical concept into sharp focus as a practical issue. The embodied aspects of students' experiences emerged as a significant 
issue from the qualitative research. In general, students had been impressed with the resources at Goldsmiths and inspired by the level of art practice. There was a sense of awe at the opportunities provided by independent studio space and a feeling that it was an environment where they 'could really work'. But some students found this 'arty' environment quite alien, using phrases such as 'stuck up'. As one black female student commented:

'They're not looking for people like us' (BTEC National Diploma student, focus group).

This reinforced the DCA team's concerns about the difficulties experienced by students encountering a university environment for the first time. The highly selective nature of the Fine Art course meant that the tried and tested outreach strategy of the university visit was of limited value for some students:

'the project is called 'Widening Participation', but then you get thirty students there and frighten the life out of them...50 places, 1600 applicants.... and you feel 'well if your face don't fit, you ain't getting in' (Carlile, 2010)

In contrast, many of the students found their experience of working regularly with Goldsmiths student ambassadors to support their portfolio development more positive. Ambassadors were described as 'really nice', 'normal' people who had made a real difference, highlighting the importance of familiarity and 'trust' previously noted by Gartland and Paczuska (2007).

We understood the importance of 'fitting in', anticipating that prospective students might not regard Goldsmiths as the 'right' place for them. But our research also revealed a negative self-perception causing them to question whether they were the 'right' students for Goldsmiths, which was highly significant in shaping their choices. Bourdieu (as quoted in Reay et al. 2001, 864) uses the notion of 'a sense of one's place' to explain the reflexive nature of this process which serves to perpetuate the existing class/ethnic/gender divisions. 
Feedback from students about their experience of the university environment indicated the extent of their alienation, resulting in changes to outreach practices and exploration of other strategies to tackle their negative perceptions. The importance of Student Ambassadors was reiterated as, despite differences in class and ethnicity, similarities in age, interests and, in this case, commitment to Art practice, allowed connections which overcame some of the concerns about 'fitting-in'.

\section{Qualifications and education}

As we have seen some social groups have a culture of accessing certain forms of art through galleries and exhibitions that relate more closely to the formal expectations of education, privileging their cultural heritage above others. Drawing on Bourdieu's 'The Love of Art' (1991), Burke and McManus explain: 'Admiration for art is not an innate predisposition; it is an arbitrary, that is, a cultural product of a specific process of inculcation' $(2009,21)$. We became aware during the course of the research how significant this particular form of knowledge was in the development of the cultural capital necessary to gain a place at Goldsmiths.

The survey data showed that while Goldsmiths students were drawn from 43 different colleges within the UK, a small number had much greater representation and a consistent success rate. Further examination revealed that these colleges were very skilled in preparing students for study at Goldsmiths, sometimes benefitting from Goldsmiths alumni on the staff. Over time, this connection resulted in a transfer of knowledge and expertise between successful students, tutors and prospective applicants, enabling them to successfully support applicants through the admissions process. One of the $2^{\text {nd }}$ year Goldsmiths students explains:

\footnotetext{
it starts a bit earlier, like what foundation (course) you get on to, and that foundation can set you up for a better uni. Ours was level 4 and we had visitors from Goldsmiths
} 
come to ours, we had lots of connections with tutors at art colleges and we worked in a way that suited Goldsmiths'.

In colleges where fewer students progress to the most selective courses, there is less contact with admissions, alumni and university staff. As the research and the outreach activities progressed, the unequal distribution of the 'right' kind of knowledge to gain admission became ever more apparent, bringing into stark focus the numerous obstacles facing the FE college students in meeting Goldsmiths requirements. Regardless of artistic potential, students from the participating colleges were struggling to compete in terms of academic and intellectual capital. FE College tutors were usually well aware of this and the underlying reasons:

'some of these students come from homes where there are no pictures on the walls, there are no books in the home' (BTEC tutor).

In many FE colleges, the expertise of the staff had developed in response to the students' need for innovative pedagogical and support strategies to enable their students to succeed, rather than being focussed on achieving progression to highly selective courses. As one Lewisham lecturer reflected;

'Complicated lives, turbulent backgrounds and serious money problems impact on their readiness to apply for prestigious universities'

Tutors in all five colleges emphasised that dealing with the obstacles facing their students was time-consuming, and left them struggling to complete basic course requirements, which began to account for the poor success rate of applicants from local colleges.

The unequal starting point of some students and the need for them to explore and develop their practice prior to the selection process was identified as an urgent and pressing need. The two-week intensive Fine Art Summer School, established as part of the initiative 
began to address this. It aimed to provide local, post-16 students at different stages in their pre-degree art education, the opportunity to experience the pedagogical environment of the BA Fine Art at Goldsmiths. Personal development of their practice and ideas was encouraged through supportive individual tutorials, mentoring by ambassadors, critical studies, artist talks and studio "crits" ${ }^{3}$ with members of academic staff. Studio space, materials and library membership were also provided as well as careers talks. The Goldsmiths Fine Art model of peer learning was emulated with three levels of students working together, and culminated in an exhibition of work.

\section{Applying to Goldsmiths}

In both the survey and the group discussions, responses to questions about students' decisions to study Art and choice of HEI revealed a very low number considering an application to Goldsmiths. For many there were practical reasons: they had not heard of Goldsmiths; it did not have the right course; or they did not want, or could not afford to study in London. For others, the decision-making process was more complex, bound up with a range of competing pressures, considerations and emotions.

A common reason for not applying to Goldsmiths was the selectivity of the course and the perception that the application process was challenging and a 'waste of a choice'. FE tutors were concerned about their students' capacity to cope with the application process which was exacerbated where little or no personal contact existed with Goldsmiths staff. The importance of FE college staff as advisers and gatekeepers was reaffirmed. They were highly

\footnotetext{
${ }^{3} \mathrm{~A}$ 'crit' is a seminar where art students present their work to a group for discussion. The purpose is for the students to receive feedback on how their work is being 'read' across different categories; aesthetic, formal, material, social, political, contextual, etc. Although they may be called different names (e.g. the Goldsmiths BA crit is known as a 'convenor') and take on different formats, crits form an important part of every art course at FE and HE throughout the UK.
} 
protective of their students, keen to help them make the right choice and extremely concerned about support once they had started their degree. In some cases, tutors actively discouraged applications because of the selective nature of the Goldsmiths Fine Art course.

Research on access to Higher Education has tended to focus on factors that shape student choice, locating the problem with the student. In contrast, Burke and McManus (2009) in 'Art for a Few' identified the admissions process itself as a critical factor. They explored selection practices in five art and design higher education institutions, undertaking interviews with staff and seventy observations of selection interviews. The findings have been highly influential in changing the discourse around admissions, illustrating that, while transparency is important, real change will only come about by 'engaging admissions tutors in reflecting on the ways that their decisions might be shaped by their (discriminatory) values and perspectives' (ibid, 46). For example, in one interview case study Nina, a working class, young black woman applying to study fashion, was asked about influences on her work. She cited hip-hop and later said she wanted to design sports tops. The session was quickly brought to a close and, although her portfolio had previously been assessed as satisfactory, the following discussion was recorded:

\footnotetext{
Interviewer one: Why should we say we're rejecting her? Interviewer two: Well she's all hip-hop and sport tops Interviewer one: We'll say that her portfolio was weak. Art for a Few (Burke and McManus pp 41-42)
}

Essentially, it was felt that Nina would not fit in - she would be a fish out of water. 'Art for a Few' highlights how cultural misrecognitions operate at the point of admissions to exclude students with different forms of cultural capital.

In order to challenge underlying assumptions around admissions 'Art for a Few' was circulated within the Art Department at Goldsmiths and a discussion of the issues took place 
at the Departmental Board. Although there were a few counter opinions, it was argued that, far from being a case of letting in 'less able' students, it was in the interests of the Department to recruit a more diverse cohort. Diversity positively contributes to the radical, argumentative, critical culture on which Fine Art thrives. In response to these discussions, and in partnership with Lewisham college staff, it was agreed to trial an interview preparation workshop run by an experienced member of the Goldsmiths Art Department. The workshop was designed to develop students' capacity to analyse and reflect on their work and included the kinds of discussions likely to come up at interview at Goldsmiths. The students were all from backgrounds without art experience or university education in their families and were markedly unfamiliar with the highly coded languages and discourses of contemporary art compared to the majority of applicants to Goldsmiths from other foundation courses. In 'The Love of Art', Bourdieu and Darbel describe this very precisely as those who have not been given the instruments which imply familiarity with art from their family or from their schooling (1991, 44-45). Therefore they employ a limited perception of art, taking categories from the experience of everyday life resulting in only a basic recognition of the object depicted. In contrast, those who recognise stylistic characteristics of periods and schools of art can offer a broader, richer or more nuanced interpretation. The workshop clearly demonstrated that, like the working-class students interviewed by Reay et al (2009) Lewisham applicants were just as hard-working and even expressed more passionate feeling for their subject than applicants from more privileged backgrounds. While working with the students revealed some very innovative art practice, it also became apparent that they would not have the capacity to successfully negotiate the highly competitive admissions process. Their portfolios were under-developed and there was only a vague understanding of what selectors were looking for. Despite having equal passion, commitment and skill, it was recognised that they were unlikely to make it through the first round. 
To address this imbalance and avoid the impersonal 'cull' of the first selection stage of the e-portfolio it was agreed to trial a process in which all Lewisham applicants would be automatically granted an interview at the second stage. Applicants were still expected to fulfil UCAS application requirements, upload a portfolio and essay on time and perform well in the interview. There was no expectation that they would be offered a place or that success was a foregone conclusion. To avoid any bias, it was agreed that the Goldsmiths lecturer who had conducted the interview preparation workshop would not sit on the interview panel. As a consequence of their performance in interview, three out of the four Lewisham College applicants were successful in gaining places on the BA Fine Art, the first time that any student from Lewisham College had been accepted. Although DCA was developed to improve progression to Goldsmiths, Lewisham staff reported that - also for the first time - all of the Foundation Year students who applied were successful in gaining a place in HE, demonstrating the additional value to widening participation through initiatives such as DCA.

\section{Creativity and commitment}

Despite the pressures highlighted above, the desire to continue studying Art was very strong for all students including those from working class and BME backgrounds. Seventy-seven per cent of BTEC students intended to progress on to a foundation diploma or degree level art course. At one college where only $20 \%$ of mothers and $30 \%$ of fathers were in employment, and only $10 \%$ of mothers and $10 \%$ of fathers were educated to degree level, $90 \%$ of the students expressed a desire to continue studying art at university. This is in direct contradiction to commonly held assumptions that 'disadvantaged' students lack the ambition to progress on to higher education. It was also clear that the 'difficult conflictual feelings' described by Reay et al. (2001, 865-6) and the anxiety faced by many students in making the 'right' choice, appeared to be amplified in relation to art and could be a source of 
disappointment and even conflict within the family. Practical considerations around income and career prospects were weighed against powerfully-felt emotional connections to art and art practice; anxiety about feeling out of place against a desire to experience the resources and creative potential afforded by a place like Goldsmiths. These conflicting and competing emotions came up repeatedly, causing the DCA team to admire and wonder at those who had chosen to continue, and to reflect on the number of talented young artists who might have been deterred from applying.

One explanation for their continuing commitment was the emotional connection that students described in relation to art, talking about their individual passion and their personal investment in the subject. As well as being something they were 'good at', a significant number of students responded to the question 'Why did you choose to study art?' in terms of personal connection, of needing to do art:

'it is the only area that never stops stimulating me'

(BTEC National Diploma student, survey data)

'I would do nothing else'

(BTEC National Diploma student, survey data)

These positive feelings emphasised the students' commitment and connection to art, qualities highly valued by admissions tutors.

\section{Reflections and Recommendations}

The DCA project illustrated that the factors militating against wider participation in the arts are deeply rooted in the social, cultural and economic fabric of our society. Given this complexity, universities often look to schools or wider society to address the issues failing to recognise the important role the sector has in promoting change and increasing student 
diversity. The section below reflects on our experience and makes some suggestions for others setting out to increase access to selective courses.

\section{Participatory Action Research}

The DCA initiative demonstrates that widening participation is possible, even for highly selective courses, but that change requires a reflexive approach that pays '...close attention to the complex and micro-level workings and relations of power and inequality in educational sites' (Burke 2012, 71). The methodology enabled us to create dynamic spaces where staff and students from different educational sectors could develop new understandings and practical actions that resulted in real change. In these exploratory, risky spaces that transgressed existing fields, it was possible to develop new forms of cultural capital - in Goldsmiths and FE staff as well as in potential and existing students. While the methodology needs development, the success of the DCA initiative indicates there is value in further refinement to support widening participation interventions. The reflexive-dialectical focus defined by Kemmis (2005) would seem to be the most valuable as it clearly embraces all participants within the process, re-affirming the need for change at all levels, not merely on the part of prospective university students.

\section{Widening Participation Interventions and Partnership}

WP outreach interventions take place at the boundaries of institutions and at points of transition requiring staff and students from different organisations to work together to create a space where new types of learning can take place. The engagement of our college partners was essential to the success of this project and a central part of the methodological approach. As a result, securing the involvement of local partners in the early stages of an intervention is highly recommended. Even when an intervention is not specifically part of a research project 
the 'shared problem' approach is very beneficial. The expertise of the University WP outreach staff in brokering these partnerships is essential, as is their high level of project management skills and in-depth understanding of the issues confronting the students and staff.

\section{Ambassadors}

While the Goldsmiths Ambassadors were pivotal to the success of the initiative, the social and cultural differences between the students were significant. FE tutors broadly welcomed the support but asked to be involved in the selection of ambassadors to ensure they would not reinforce perceptions of cultural divisions. The whole team agreed that encouraging local FE student alumni to become ambassadors had great potential. However, there is a fine balance in formulating the ambassador team to include those where there is an immediate cultural connection as well as with those from different backgrounds in order to challenge existing habitus.

Ambassadors need effective training for work on complex interventions such as DCA which are essentially about developing cultural, intellectual and academic capital very different from early 'aspiration raising' widening participation activities. In interventions like DCA, they are working as change agents alongside the outreach and academic staff and the aims and nature of the work must be explicit if learning and change are to take place.

\section{Academic Staff}

Even the most experienced and well-trained ambassadors have limited impact in this type of intervention. At certain points the involvement of academic staff is essential as they are the final arbiters of what counts as valid academic and intellectual capital. When academic staff work directly with the FE students and their teachers it is possible to explore this almost tacit knowledge and develop the skills and understandings required to make a successful 
application. Direct engagement also enables the academic staff to develop their own understandings of the issues and reflect on and change their practices. In this case the DCA initiative had full support from the Head of Department which allowed the staff to act on their findings and adapt their admissions practices accordingly, resulting in immediate change.

\section{Learning and Teaching}

It became clear during the course of the initiative that, in addition to social justice concerns, there are good intellectual and pedagogical reasons to widen participation. In the case of contemporary art, successful practice is centred on creativity and originality. HEIs aim to foster this by providing an environment where students can extend their practice and reflect on their work, becoming part of a 'learning community' utilising their individual, unique perspectives. One Goldsmiths tutor observed in the first term that more diversity in the cohort was bringing new perspectives to seminar debates. Notably, dialogue could occur outside a presumptive position of art, revealing the value of alternative perspectives. The group was not assuming a singular art audience but imagining it expanded and re-enlivened.This was especially enriching in the studio 'crit', where a particular student's work and ideas are explored in and across different social, artistic and intellectual contexts. For the group as a whole, increased diversity brought to light the exclusionary languages of contemporary art and the processes through which the audience for art becomes exclusive and elitist. The field itself was challenged by these new perspectives, resulting in a dynamic learning and teaching moment for both lecturer and students with discussions intervening and extending the field.

\section{Employability}

The research brought to the fore the importance of making explicit to all prospective students the diverse range of career opportunities available. Fine Art graduates can develop a range of 
skills that are useful in the labour market but often these are not explained to current or prospective students, or indeed employers. For example, at Goldsmiths students are expected to stage their third year show independently, a challenging task which in other contexts would be described as work experience or employability skills. If these existing elements of the degree were enhanced, accredited and publicised this would benefit all students but particularly those from backgrounds more immediately concerned about employability.

\section{Supporting Students}

Increasing the diversity on the BA Fine Art course was a significant achievement but it also highlighted the importance of having support in place for those students who need it. The evidence from the first year suggests that, once on the course, the experience of students is mixed. For some, gaining a place on one of the top Fine Art courses in the country has clearly boosted their self confidence as artists and they have thrived on the rigorous environment of the BA Fine Art. Despite challenging circumstances, they have a picture of themselves as artists with something worth communicating. For others, cultural ideas about studying art have caused conflict at home. For those students with special educational needs, the sheer amount of information to take in at the start of the course has been particularly challenging.

\section{Student success}

Nevertheless, the initiative not only resulted in successful admissions for five students from Lewisham and another local college for the first time, but all achieved good grades in their first year and progressed on to Level 2. There are also significant successes; one of these local students achieved outstanding marks in critical studies, another was awarded the Painters Scholarship, given to the most promising painter of the first year cohort. This award provides 
$£ 5,000$ per year for the remaining two years of study on the programme, allowing this particular student to visit Iran to follow up on the issues she was exploring in the sequence of paintings that so impressed the external awarding panel.

\section{Conclusion}

The field of higher education has its own particular cultures and practices, privileging some and excluding others (Naidoo 2004). Increased recognition of this can enable university staff involved in widening participation to accept that they must be prepared to learn, reflect and change to avoid slipping into a deficit framework and effect real change. For those involved in the DCA initiative the immediate, positive impact on progression of the college students was and remains transformative. It demonstrated that it is possible to develop cultural capital through engagement in these challenging and risky spaces. As Mills $(2008,84)$ states, 'by broadening the types of cultural capital that are valued in the classroom ... teachers can act as agents of transformation rather than reproduction.'

The DCA initiative also illustrates how social and cultural diversity amongst the student body can enhance the intellectual and social life of the university, benefitting all students and their teachers. It demonstrates that widening participation need not be equated with lower standards, but with renewal and positive change. It also reminds us that Universities are powerful vehicles in forming and conveying cultural norms and practices. Engaging with widening participation initiatives demonstrates that higher education understands the impact that social, economic and cultural factors have on attainment and progression. It also sends a strong message that universities value diversity amongst staff and students and recognise its value in supporting excellence and fostering creativity. 


\section{References}

Archer, L., M. Hutchings and A. Ross. 2003. Higher Education and Social Class: Issues of exclusion and inclusion. London and New York: RoutledgeFalmer.

Archer, L., and C. Leathwood. 2003. "Identities, Inequalities and Higher Education.” In Higher Education and Social Class: Issues of exclusion and inclusion edited by L. Archer, M. Hutchings and A. Ross, 175 - 191. London and New York: RoutledgeFalmer.

Archer, L. and M. Hutchings. 2004. "Bettering Yourself? Discourses of risk, cost and benefit in ethnically diverse, young working-class non-participants' constructions of higher education." British Journal of Sociology of Education 21(4): 555-574

Boliver, V. 2011. "Expansion, differentiation and the persistence of social class inequalities in British higher education." Higher Education 61 (3): 229-242

Bourdieu, P. 1984. Distinction: A social critique of the judgement of taste. London: Routledge.

Bourdieu, P., and A. Darbel. 1991. The Love of Art. Cambridge: Polity Press

Bourdieu, P., and L.J.D. Wacquant. 1992. An Invitation to Reflexive Sociology. Chicago: University of Chicago Press

Bourdieu, P. 1993. The Field of Cultural Production. Cambridge: Polity Press.

Burke, P. J. 2006. "Men accessing education: gendered aspirations." British Education Research Journal 32 (5): 719 - 733.

Burke, P. J. 2009. "Men Accessing Higher Education: Theorising continuity and change in relation to masculine identities." Higher Education Policy 22 (1): 81-100.

Burke, P. J., and J. McManus. 2009. Art for a Few: Exclusion and Misrecognition in Art and Design Higher Education Admissions. London: National Arts Learning Network

Burke, P. J. 2012. The Right to Higher Education. Abingdon: Routledge.

Carlile, A. 2010. Choosing, applying for, and getting on to an art degree at Goldsmiths or similar universities. Research Report, Department of Education Studies, Goldsmiths, University of London.

Coleman, J. S. 1988. Social capital in the creation of human capital. American Journal of Sociology 94: 95-120. 
Ecclestone, K., and J. Field. 2003. 'Promoting Social Capital in a 'Risk Society': A new approach to emancipatory learning or a new moral authoritarianism?" British Journal of Sociology of Education 24 (3): 267-282

Francis, B. 2000. "The Gendered Subject: Student preferences and discussions of gender and subject ability." Oxford Review of Education 26 (1): 35-48

Gamarnikow, E., and A. Green. 1999. "Developing Social Capital: Dilemmas, Possibilities and Limitations in Education." In Tackling Disaffection and Social Exclusion: Education Perspectives and Policies, edited by. A. Hayton, 46-64. London: Kogan Page.

Gartland, C., and A. Paczuska. 2007. "Student ambassadors, trust and HE choices." Journal of Access Studies 4 (2): 108-133

Gewirtz, S. 2001 . "Cloning the Blairs: New Labour's programme for the re-socialization of working-class parents.” Journal of Educational Policy 16 (4): 365-378.

Harris, M. 2010. What more can be done to widen access to highly selective universities? Bristol: Office for Fair Access.

Heisanken, T. 2007. "Pursuing Theory and Practice when 'Everything is Moving'." Journal of Adult and Continuing Education 13 (2): 175-191

Kemmis, S. 2005. "What is Professional practice? Recognising and respecting diversity in understandings of practice.” In Elaborating Professional Practice, ed. C. Kanes. London: Springer.

Leathwood, C., and A. Hayton. 2002. "Educational Inequalities in the UK: A critical analysis of the discourses and policies of New Labour." Australian Journal of Education 46 (2): $138-153$

Mills, C. 2008. "Reproduction and transformation of inequalities in schooling: the transformational potential of the theoretical constructs of Bourdieu." British Journal of Sociology of Education 29 (1): 78-89.

Naidoo, R. 2004. "Fields and institutional strategy: Bourdieu on the relationship between higher education, inequality and society." British Journal of Sociology of Education 25 (4): 457-471. 
Navarro, Z. 2006. In Search of a Cultural Interpretation of Power: The Contribution of Pierre Bourdieu. IDS Bulletin, 37: 11-22.

Putnam, R. D. 1995. “Bowling Alone; America's Declining Social Capital. ”Journal of Democracy 6 (1): 65-78

Reason, P., and H. Bradbury. 2008. "Introduction.” Sage Handbook of Action Research; Participative Inquiry and Practice. $2^{\text {nd }}$ ed. London, California, New Delhi, Singapore: Sage.

Reay, D., M. David, and S. Ball. 2005 . Degrees of choice: class, race, gender and higher education. Stoke-on-Trent: Trentham Books.

Reay, D., J. Davies., M. David., and S. Ball. 2001. "Choices of Degree or Degrees of Choice: Class, Race and the HE Choice Process.” Sociology 35 (4): 855-874.

Reay, D. 2004. 'It's all becoming a habitus: beyond the habitual use of habitus in educational research.” British Journal of Sociology of Education 25 (4): 431-444

Reay, D., G. Crozier, and J. Clayton. 2009. "Strangers in Paradise? Working-class Students in Elite Universities.” Sociology 43 (6): 1103-1131

Robbins, D. 2000. Bourdieu and Culture. London: Sage Publications.

Sennett, R. 2009. The Craftsman. London: Penguin.

Shiner, M., and T. Modood. 2002. "Help or Hindrance? Higher Education and the route to ethnic equality." British Journal of Sociology 23 (2): 209-232

Somekh, B., and K. Zeichner. 2009. "Action Research for Educational Reform: remodelling action research theories and practices in local contexts." Educational Action Research 17 (1): $5-21$

Sutton Trust. 2011. Degrees of Success: University Chances by Individual School. London: Sutton Trust.

Vignoles, A., and C. Crawford. 2010. “Access, participation and diversity questions in relation to different forms of post-compulsory further and higher education." In Improving learning by Widening Participation in Higher Education, edited by M. David, 47-61. Abingdon: Routledge.

Williams, Z. 2006. http://www.guerrillagirls.com/posters/Bronxgetmad.shtml, 
Williams, Z. 2006. Going Ape. The Guardian, June 29, London edition 